\title{
A New Murine Model of Persistent Lung Eosinophilic Inflammation
}

\author{
Momtchilo Russo ${ }^{+}$, Mario Mariano, Sonia Jancar \\ Departmento de Imunologia, Instituto de Ciências Biomédicas, ICB-III, Universidade de São Paulo, Av. Profes-
sor Lineu Prestes 2415, 05508-900 São Paulo, SP, Brasil
}

We summarize here the main characteristics of a novel model of pulmonary hypersensitivity. Mice were immunized with a subcutaneous implant of a fragment of heat solidified chicken egg white and 14 days later challenged with ovalbumin given either by aerosol or by intratracheal instillation. This procedure induces a persistent eosinophilic lung inflammation, a marked bone marrow eosinophilia, and Th2-type isotypic profile with histopathological findings that resemble human asthma. Further, this model is simple to perform, reproducible in different strains of mice, does not require adjuvants nor multiple boosters. Based on these characteristics we propose it as a suitable murine model of allergic eosinophilic lung inflammation.

Key words: asthma - late-phase reaction - eosinophil - mice - eosinophil peroxidase

Asthma is a chronic inflammatory disease of the airways and its incidence is increasing in urban environments. It is characterized by intermittent, reversible airway obstruction and by bronchial hyperreactivity. Nearly a century ago it was observed that eosinophils are the major cell type infiltrating into the airways of asthmatic patients (Ellis 1908). Based on data obtained in animal models of asthma, it has been proposed that $\mathrm{T}$ cellderived cytokines, namely IL-4 and IL-5, play a central role in the induction of lung eosinophilic inflammation. IL-4 is a key cytokine for IgG1 and IgE isotype switching (Drazen et al. 1996), whereas IL-5 is required for the mobilization and migration of eosinophils to the lung (Walker et al. 1991, Nakajima et al. 1992). Indeed, it was shown that IL-4 or IL-5 knockout mice immunized with ovalbumin failed to develop airway hyperresponsiveness after OVA aerosol challenge (Corry et al. 1996, Foster et al. 1996). Major advances in the understanding of the mechanisms involved in the pathogenesis of asthma came from studies using animal models. A great variety of experimental models have been developed; most of them involve immunization with adjuvants, usually Alum and multiple antigen boosters.

We have recently reported that immunization of mice with a subcutaneous implant of fragments

This work was supported by grants from FAPESP and CNPq.

${ }^{+}$Corresponding author. Fax: +55-11-818.7377. E-mail: momrusso@biomed icb2.usp.br

Received 3 September 1997

Accepted 30 September 1997 of heat-coagulated chicken egg white (EWI) without adjuvant was able to induce a typical late-phase reaction with a prominent eosinophilic infiltrate after ovalbumin challenge into the footpad (Facincone et al. 1997). We have then adapted this model to induce a late-phase reaction in mouse lungs. For this, mice were immunized with EWI implanted into the subcutaneous tissue and challenged with heat aggregated OVA instilled into the trachea 14 days later. It was found that $48 \mathrm{hr}$ after challenge a high percentage of eosinophils was found in the BAL (35\%) and increased levels of EPO activity were found in lung homogenates. These results were reproduced in five different mouse strains. Compared to another five models of lung hypersensitivity, the EWI model was the only one to induce eosinophilia which persisted for 30 days. The histopathological findings confirmed the intense eosinophilia and resembled those of human asthma (de Siqueira et al. 1997).

In this study we have further characterized this model by analyzing: (a) the efficacy of challenge with aerosolized ovalbumin, (b) the effect of immunization with different concentrations of chicken egg white antigens on airway and bone marrow eosinophilia and (c) the isotypic profile of antibody production. More importantly, we outline the main characteristics of this new experimental model of asthma.

\section{MATERIALS AND METHODS}

Immunizations protocols for the induction of pulmonary eosinophilia - Group of B6 mice were immunized with $100 \mu \mathrm{g}$ OVA (grade III, Sigma Chemical Co.) adsorbed to $1.4 \mathrm{mg}$ of alum (OVAAlum) injected intraperitoneally or with a fragment 
of solidified chicken egg white (EWI) implanted subcutaneously in the dorsal flank of mice through a 5-mm-long cut in the skin. The EWI was prepared in two different ways: (a) separated chicken egg white was placed in a water bath at $100^{\circ} \mathrm{C}$ for $30 \mathrm{~min}$; the solidified egg white was washed in distilled water, dehydarated in $100 \%$ ethanol for $48 \mathrm{hr}$ and cut in to small fragments of $4 \times 2 \times 2 \mathrm{~mm}$ weighing around $40 \mathrm{mg}$ each and rehydrated in Dulbecco's PBS for $2 \mathrm{hr}$ before implantation or (b) 10 or $20 \%$ solutions of chicken egg white were prepared by dissolving pasteurized and dehydrated chicken egg white (Ito-Avicultura Ind. e Com. S.A., SP, Brazil) in sterile water. A volume of $30 \mu 1$ of the egg white solutions, containing $3 \mathrm{mg}(10 \%)$ or $6 \mathrm{mg}(20 \%)$, of egg white, were placed onto glass slides with 12 wells and heat-coagulated in a microwave oven set at maximum potency for $2 \mathrm{~min}$. The solidified fragments of egg white were then fixed in absolute ethanol for $48 \mathrm{hr}$ and rehydrated in Dulbecco's PBS for $2 \mathrm{hr}$ before subcutaneous implantation. Fourteen days after the immunizations the animals were challenged by exposure to an aerosol of OVA (grade III, Sigma) at concentration of $25 \mathrm{mg} / \mathrm{ml}$ in $0.9 \%$ saline generated by an ultrasonic nebulizer (ICEL US-800, SP, Brazil) delivering particles of $0.5-10 \mu \mathrm{m}$ of diameter at aproximately $0.75 \mathrm{cc} / \mathrm{min}$ for $20 \mathrm{~min}$.

Determination of OVA-specific isotypes - Antiovalbumin antibodies were assayed by ELISA as previously described (Mengel et al. 1995). Briefly, the Nunc-Immuno Plate MaxiSorp (Inter Med, SP, Brazil) were coated with $2 \mu \mathrm{g}$ of OVA per well, blocked with $0.25 \%$ casein in PBS and incubated with two-fold dilutions (1/100 to $1 / 12,800)$ of mouse sera. The bound antibodies were revealed by goat anti-mouse IgM, IgG1, IgG2a, IgG2b, IgG3 and IgA followed by peroxidase conjugated rabbit anti-goat-Ig antibody (Southern Biotechnology, Birmingham, AL) and finally by $o$-orthophenylenediamine dihydrochloride (OPD) (Sigma). The reaction was stopped by addition of $50 \mu$ of $4 \mathrm{M} \mathrm{H}_{2} \mathrm{SO}_{4}$ and the absorbance of the samples determined at $490 \mathrm{~nm}$. ELISA scores were computed by running sums of O.Ds. from $1 / 100$ to $1 / 12.800$ serum dilutions. Each value represents the mean \pm S.D from 5 individual mice.

Determination of OVA-specific IgE - OVA-specific IgE antibodies were evaluated by passive cutaneous anaphylaxis (PCA) assay as described by Mota and Wong (1969).

Eosinophil peroxidase (EPO) activity - The EPO activity present in bronchoalveolar lavage cells (BAL) and in bone marrow cells was determined with a colorimetric assay as described by Strath et al. (1985) with minor modifications. In brief, cell suspensions were collected as described elsewhere and exposed to Tris- $\mathrm{NH}_{4} \mathrm{Cl}$ buffer to lyse erytrocytes. The cells were then washed once with PBS and adjusted to $10^{6} \mathrm{cells} / \mathrm{ml}$. $100 \mu \mathrm{l}$ were transferred into wells of 96-well microplate in duplicate. The microplates were then centrifuged at $1,000 \mathrm{rpm}$ at $4^{\circ} \mathrm{C}$ for $10 \mathrm{~min}$, after which the supernatants were carefully discarded and $100 \mu \mathrm{l}$ of substrate solution containing $4 \mathrm{mg}$ of OPD in $50 \mathrm{mM}$ Tris- $\mathrm{HCl}, \mathrm{pH} 8.0$ and $10 \mu \mathrm{l}$ of $\mathrm{H}_{2} \mathrm{O}_{2}$ added to each well. The plates were incubated at room temperature for $15 \mathrm{~min}$. The reaction was stopped by addition of $50 \mu \mathrm{l}$ of $4 \mathrm{M} \mathrm{H}_{2} \mathrm{SO}_{4}$ and the absorbance of the samples determined at $490 \mathrm{~nm}$.

Bone marrow cell harvesting - Bone marrow cells were obtained by flushing mice femurs with $1 \mathrm{ml}$ of PBS. The cell suspensions were gently homogenized to break up large clumps, submitted to lysing buffer as described above for BAL, counted in a hemacytometer and resuspended to the desired concentration.

\section{RESULTS AND DISCUSSION}

The effect of different concentrations of egg white on pulmonary and bone marrow eosinophilia - The EPO activity assay was employed to detect eosinophils in different compartments (Strath et al. 1985). The levels of EPO activity, a specific enzyme of eosinophils, were determined in bronchoalveolar cells and in bone marrow cells. Groups of five mice were immunized with different concentrations of EWI or with OVA-Alum (for comparison) and the EPO activity was measured seven days after OVA aerosol challenge. As shown in Table, the levels of EPO activity detected in the EWI groups were significantly higher than those obtained in OVA-Alum group. Surprisingly, no significant differences were observed in EPO activity among the groups immunized with EWI at different antigen concentrations. Thus, in these experimental conditions, the intensity of pulmonary and bone marrow eosinophilia was not dependent on the concentration of egg white used for immunization.

OVA-specific isotype profile in mice immunized with EWI - The profile of OVA-specific isotype production was evaluated in the serum of five mice immunized with EWI seven days after exposure to $2.5 \%$ aerosolized OVA for $20 \mathrm{~min}$. As shown in Fig. this type of immunization induced an increased secretion of $\operatorname{IgM}, \operatorname{IgG} 1$ and $\mathrm{IgE}$ anti-OVA antibodies, but not of IgG2a, IgG2b or IgA isotypes.

We conclude that EWI immunization promoted a selective Th2-mediated antibody production characterized by high levels of IgG1 and IgE and low levels of $\operatorname{IgG} 2 \mathrm{a}, \operatorname{IgG} 2 \mathrm{~b}$ and $\operatorname{IgA}$. Moreover, the experiments reported here confirm and extend our previous work (de Siqueira et al. 1997) and docu- 
TABLE

Effect of different concentration of egg white on eosinophil peroxidase activity (EPO)

\begin{tabular}{lcc}
\hline \multirow{2}{*}{$\begin{array}{l}\text { Immunization } \\
\text { protocols }\end{array}$} & \multicolumn{2}{c}{ EPO activity at $490 \mathrm{~nm}$} \\
\cline { 2 - 3 } & $\begin{array}{c}\text { Bronchoalveolar } \\
\text { cells }\end{array}$ & $\begin{array}{c}\text { Bone marrow } \\
\text { cells }\end{array}$ \\
\hline EWI $40 \mathrm{mg}^{a}$ & $\mathbf{1 . 5 5 3} \pm \mathbf{0 . 0 6 2}$ & $\mathbf{0 . 5 4 4} \pm \mathbf{0 . 0 1 0}$ \\
EWI $6 \mathrm{mg}^{b}$ & $\mathbf{1 . 4 8 3} \pm \mathbf{0 . 0 2 0}$ & $\mathbf{0 . 4 3 5} \pm \mathbf{0 . 0 2 5}$ \\
EWI $3 \mathrm{mg}^{b}$ & $\mathbf{1 . 8 9 8} \pm \mathbf{0 . 0 9 8}$ & $\mathbf{0 . 5 5 5} \pm \mathbf{0 . 0 2 9}$ \\
OVA-AL & $0.653 \pm 0.316$ & $0.221 \pm 0.128$ \\
\hline
\end{tabular}

Five B6 mice per group were immunized with EWI and challenged 14 days later with aerosolized OVA as described in detail in M\&M section. Values in bold lettering indicate significant differences between EWI groups vs OVA-AL.

$a$ : fresh egg white was heat-coagulated in water-bath as described in detail in M\&M section, fragments of 40 mg were implanted into the subcuatenous tissue.

$b$ : pasteurized and dehydrated egg white powder reconstituted to 20 or $10 \%$ with sterile water was heatcoagulated in microoven as described in M\&M section, fragments containing 6 or $3 \mathrm{mg}$ were implanted s.c.

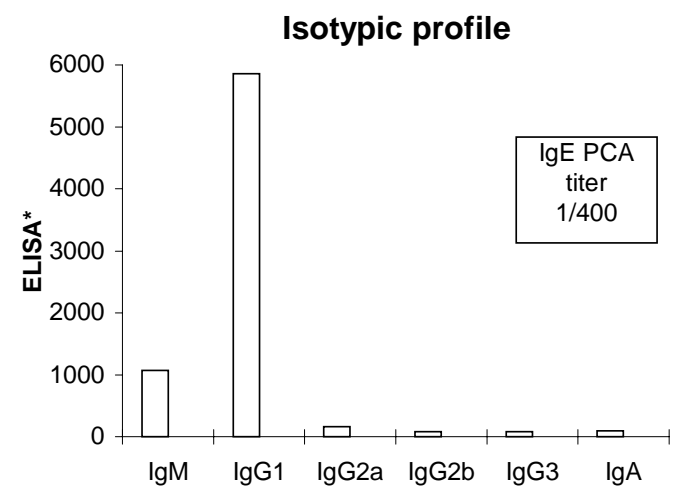

Isotype profile of immunized mice after OVA aerosol challenge. B6 mice were immunized with EWI and 14 days later exposed to aerosolized OVA for $20 \mathrm{~min}$ as described in Materials and Methods. Serum samples were collected individually and assayed for OVA-specific IgM, IgG1, IgG2a, IgG2b, IgG3 and IgA antibodies by ELISA*. Results are expressed as sums of ODs readings at $490 \mathrm{~nm}$ ranging from $1 / 100$ to $1 / 12800$ serum dilutions. The $\operatorname{IgE}$ titers were determined by standard passive cutaneous anaphylaxis assay (PCA). Values represent the media of 5 individual mice. Results are representative of one out three experiments run independently.

ment that EWI immunization led to a higher eosinophil production and a more persistent airway eosinophilia than OVA-Alum.

The mechanism by which EWI immunization leads to persistent lung eosinophilia remains to be determined. Recently it has been shown that mice that lack the IFN- $\gamma$ receptor present a persistent lung eosinophilic infiltration following OVA challenge (Coyle et al. 1996). We speculate that in the
EWI model, the production of IFN- $\gamma$ should be negligible because as shown in Fig., the production of IgG2a or IgG3 isotypes which are known to be dependent on IFN- $\gamma$ production (Stavnezer 1996) was almost absent. Thus it is possible that a selective suppression of IFN- $\gamma$ production may occur in our model. Interestingly, Guéry et al. (1996) showed that protein antigens delivered continously by mini-osmotic pump implanted subcutaneously, induced a long-lasting inhibition of IFN- $\gamma$ production. By analogy, the egg white implant may act like a mini pump releasing low amounts of solubilized OVA continously. These possibilities are now under investigation.

Finally, based on the data presented here and on data of two recent papers (Facincone et al. 1997, de Siqueira et al. 1997) published by our group, we summarize the most relevant findings in the EWI model. First, it is simple to perform, cheap and reproducible in different strains of mouse and different species, such as rats where it also induces bronchial hyperreactivity (Carvalho et al. in preparation). Second, the model does not require adjuvant or immunization with multiple boosters. Third, it exhibits a Th2-associated isotypic profile and a typical late-phase reaction. Fourth, it induces long lasting pulmonary and bone marrow eosinophilia and lung lesions that may resemble those found in human asthma.

\section{ACKNOWLEDGEMENTS}

To Eliane Gomes for expert technical assistance.

\section{REFERENCES}

Corry DB, Folkesson HG, Warnock ML, Erle DJ, Matthay MA, Wiener-kronish JP, Locksley RM 1996. Interleukin 4, but not Interleukin 5 or eosinophils, is required in a murine model of acute airway hyperreactivity. J Exp Med 183:109-117.3.

Coyle AJ, Tsuyuki S, Bertrand C, Huang S, Aguet M, Alkan SS, Anderson GP 1996. Mice lacking the IFN$\gamma$ receptor have an impaired ability to resolve a lung eosinophilic inflammatory response associated with a prolonged capacity of $\mathrm{T}$ cells to exhibit a Th2 cytokine profile. J Immunol 156: 2680-2685.

de Siqueira ALP, Russo M, Steil AA, Facincone S, Mariano M, Jancar S 1997. A new murine model of pulmonary eosinophilic hypersensistivity: Contribution to experimental asthma. J Allergy Clin Immunol 100: 383-388.

Drazen JM, Arm JP, Austen KF 1996. Sorting out the cytokines of asthma. J Exp Med 183: 1-5.

Ellis AG 1908. The pathological anatomy of bronchial asthma. Am J Med Sci 136: 407-410.

Facincone S, Pereira de Siqueira AL, Jancar S, Russo M, Barbuto JAM, Mariano M 1997. A novel murine model of late-phase reaction of immediate hypersensitivity. Mediators of Inflammation 6: 127-133.

Foster PS, Hogan SP, Ramsay AJ, Matthaei KI, Young 
IG 1996. Interleukin 5 deficiency abolishes eosinophilia, airways hyperreactivity, and lung damage in a mouse asthma model. J Exp Med 183: 195-201.

Guéry J-C, Galbiati F, Smiroldo S, Adorini L 1996. Selective development of T helper (Th) 2 cells induced by continuous administration of low dose soluble proteins to normal and $\beta 2$-microglobulin-deficient BALB/c mice. J Exp Med 183: 485-497.

Mengel J, Cardillo F, Aroeira LS, Willians O, Russo R, Vaz NM 1995. Anti- $\gamma \delta$ T cell antibody blocks the induction and maintenance of oral tolerance to ovalbumin in mice. Immunol Letters 48: 97-102.

Mota I, Wong D 1969. Homologous and heterologous passive cutaneous anaphylactic activity of mouse antisera during the course of immunization. Life Sci 8: 813-823.
Nakajima H, Iwamoto I, Tomoe S, Matsumara R, Tomioka H, Takatsu K, Yoshida S 1992. CD4 ${ }^{+}$Tlymphocytes and interleukin-5 mediate antigen-induced eosinophil infiltration into the mouse trachea. Am Rev Respir Dis 144: 374-377.

Stavnezer J 1996. Immunoglobulin class switching. Curr Opin Immunol 8: 199-205.

Strath M, Warren DJ, Sanderson CJ 1985. Detection of eosinophils using an eosinophil peroxidase assay. Its use as an assay for eosinophil differentiation factors. J Immunol Methods 83: 209-215.

Walker C, Virchow Jr JC, Bruijnzeel PL, Blaser K 1991. $\mathrm{T}$ cell subsets and their soluble products regulate eosinophilia in allergic and nonallergic asthma. JImmunol 146: 1829-1835. 